partners of two general practices in East Anglia, that the increase in lifespan which has resulted from advances in medical science and public health should not be years of a "prison sentence" but should be enjoyed.

Surely to advise elderly patients against going on holiday simply because they may fail to take some necessary medicine would be a complete travesty of this philosophy?

Addenbrooke's Hospital,

Virginia Alun Jones Cambridge

\section{Preventing postoperative} thromboembolism

SIR,-We were interested to read the letter of Professor C A Wells (14 July, p 129) on "standing Fowler on his head." The apparent effect of "one pillow, nine-inch blocks at the foot of the bed, active leg exercises, and deep breathing" is that of reduction of the incidence of postoperative pulmonary embolism, although he does not present figures to support this. Presumably such an effect would be mediated by reduction in venous stasis, the third factor in Virchow's triad. With the abundance in recent years of trials on drugs which produce biochemical changes to reduce thromboembolism this area of research has perhaps been rather overlooked.

Professor Wells excludes "orthopaedic prosthetic procedures," but we think that his comments may also be valid in this area. After total hip replacement thromboembolism is particularly troublesome, and so at Gartnavel General Hospital, Glasgow, the fibrinogen uptake test and venography have been used since 1975 in the detection of deep venous thrombosis after hip replacement. During anterior-posterior screening of the venogram in these patients we noticed what appeared to be "hold-up" of the contrast at the level of the prosthesis (fig 1). This was a constant feature. Interested in this, we carried out a number of venograms, which included a lateral "shoot-through" film at the level of the hip prosthesis (fig 2). We then realised, although we should have known it already, that even if the patient's leg is supine, there is a $30^{\circ}$ gradient which the "deep" venous blood must ascend, from behind the knee

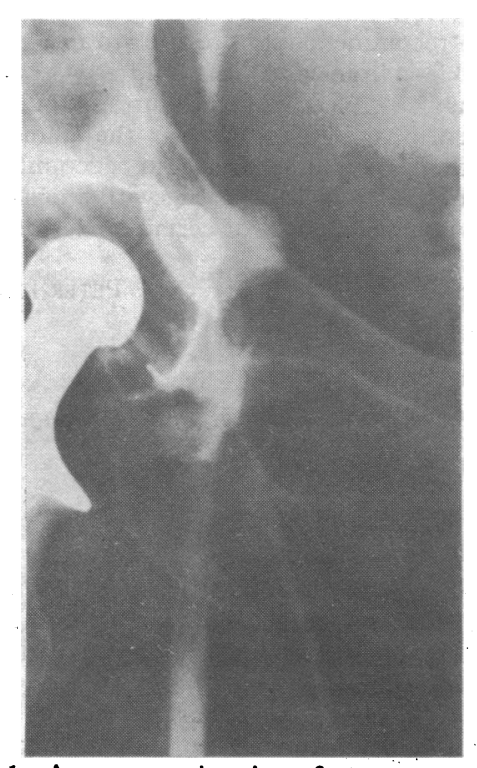

FIG 1-Anteroposterior view of venogram.

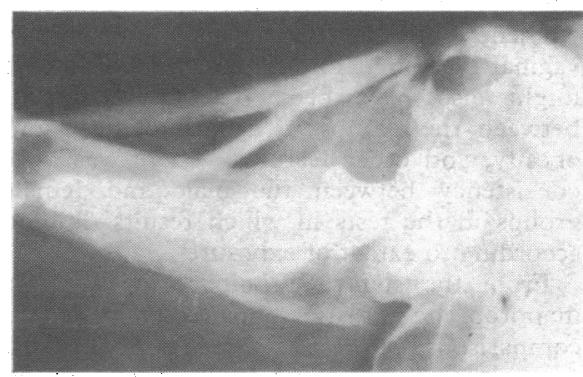

Fig 2-Lateral view of the femoral vein containing contrast.

(the popliteal vein) to the front of the hip (the superficial femoral vein). The summit of this incline is the pelvic brim, after which the external iliac vein descends into the pelvis (fig 2).

The anatomy of this region thus predisposes to venous stasis in the leg. The presence of the tight inguinal ligament may also contribute. Insertion of a hip prosthesis may worsen this obstruction to flow, by local haematoma, oedema, or even excess cement, by direct impingement. In support of this we have found deep venous thrombosis to be commoner and more extensive in the operated leg. ${ }^{1}$

The literature on this aspect of the pathogenesis of deep venous thrombosis after hip surgery is scanty, but Hartman et al ${ }^{2}$ showed a reduction in deep venous thrombosis after hip fractures in patients in whom the bed end had been elevated by $20-25^{\circ}$. Perhaps hip replacement patients should also be nursed in this way.

Victoria Infirmary,

JAMES R LOUDON Glasgow

\section{GERALD MCGARRITY \\ IAN G KELLY \\ P S RAE}

Gartnavel General Hospital,

RAMSAY VALLANCE

Glasgow

${ }^{1}$ Loudon, J R, et al, British fournal of Surgery, 1978, L5, 616.

Hartman, J T, Altner, P C, and Freeark, R J, fournal
of Bone and foint Surgery, 1970, 52A, 1618 .

\section{Umbilical hernia in child swimmers}

SIR,-The major exertion in swimming apart from the use of the limbs is in breathing control. Forced exhalation is produced by simultaneous contraction of the diaphragm and abdominal muscles in the short time that the head is above water in the swimming cycle.

As the parent of two children who are keen swimmers $I$ often attend their training sessions. A year ago I saw a 9-year-old boy lifted from the water during a hard training session with excruciating abdominal pain. I was told that this had happened to him several times in the preceding months.

On examination there was gross spasm of the abdominal muscles, respiration was rapid - from his exertion-and splinted, and pain was referred to the umbilicus. Within the umbilicus I could feel a small, tense hernia. We laid him flat and persuaded him to relax, and as his breathing excursions lessened I reduced the hernia. The boy was referred to Mr David Dunn, who repaired the hernia.

I have recently seen the exact pattern again in another child. The important physical sign is the recognition of the hernia during violent physical exercise. Recognition of the cause of the pain is.important to the child, who might otherwise be unjustly labelled as a "functional" complainer. In years of swimming coaching I have never seen this malady in adult swimmers. Increasing emphasis on child "age group" competition in swimming clubs makes it important to recognise this cause of umbilical hernia.

A wider issue is also called to mind. In 30 years of swimming I have never seen a case of abdominal "cramp" in a swimmer, though it looms large in the folklore of deaths by drowning. Could it be that the unrecognised hernia in years past could be the cause of this "cramp" ? I would be interested to hear from correspondents on this matter.

F D SKIDMORE

Royal Aberdeen Children's Hospital,

Cornhill Road,

Aberdeen AB9 2ZG

\section{Diving and hypothermia}

SIR,-The multifaceted safety structure built into diving, whether for. sport, scientific research, commercial enterprise, or military goals, implies that the majority of diving accidents are multifactorial in origin. That hypothermia can be a major contributing factor has been known by divers for many years. Indeed, the 1966 edition of the British Sub Aqua Club Diving Manual stated, "Cold can be an insidious killer."1

On the basis of a study of cold water scuba diving, Davis and others ${ }^{2}$ advocated the use of continuous deep body temperature monitoring for all extended diving in temperate or cold waters. Several of the subjects in this study became dangerously cold in water at $5^{\circ} \mathrm{C}$ in less than one hour but still persevered with their underwater tasks, their dives having to be terminated by the surface support team. In another study ${ }^{3}$ the practicability of a monitoring technique based on an ingested temperature-sensitive radio pill was established for the umbilicalled diver.

The report by Drs M G Hayward and W $R$ Keatinge (5 May, p 1182) on symptomless hypothermia is most timely in highlighting once again a serious problem. However, they are incorrect in assuming that "standard practice during deep dives is to flood the suit continuously with warm water. ..." The vast majority of diving conducted around British and New Zealand coasts is on air-using scuba apparatus and utilises either neoprene wet suits or constant-volume dry suits without any form of external heating. Under these circumstances the problem becomes one of educating the diver if such fatalities are to be avoided.

F M Davis

Department of Anaesthesia,

Christchurch Hospital,

Christchurch, New Zealand

${ }^{1}$ British Sub Aqua Club, Diving Manual, 5th edn. London, Eaton Publications, 1966.

2 Davis, F M, Baddeley, A D, and Hancock, $T$, Undersea Biomedical Research, 1975, 2, 195.
. Drew, J N Lt al, in Underwater Research, ed E A Drew, J N Lythgoe,
Academic Press, 1976.

\section{Heatwave deaths and drugs affecting temperature regulation}

SIR,-Surgeon Captain F P Ellis's letter (21 August 1976, p 474) regarding heatwave deaths and drugs affecting temperature 
regulation puts forward a most important concept. Several authors have emphasised that heatstroke can be prevented if prophylaxis is tailored to a specific population and risk. In the elderly prophylaxis of heat stroke may involve family, social services, and nursing outreach programmes. The focus should be on decreasing physical activity and changing the type and amount of bedding and clothing, as well as achieving adequate air conditioning.

The possibility of stopping medication during the heatstroke season is a very important one. Anyone who takes diuretics, amphetamines, alcohol, or any one of the large group of anticholinergics available should not only be excluded from strenuous activity but probably should have the dosage decreased during the period when the temperature humidity index is excessive.

During our most recent heatstroke epidemic, in July 1977, we saw extensive numbers of cases of heatstroke. Of these, 18 presented to one emergency service. The age range of these heatstroke victims was between 27 and 97 years of age. In this sample four individuals were using psychotropic medication and nine of the 18 subjects had a prehospital history of neurological or psychiatric disturbances or both. The drugs involved were in particular phenothiazines and tricyclic antidepressants. In addition, a group was taking anti-Parkinsonian and antispasmodic drugs. Other medications that seemed to have a significant correlation were antihypertensive medications, diuretics, and oral hypoglycaemic medications. It was therefore our feeling that to the wellrecognised risk factors of increased age, obesity and medical illnesses, one must add having psychiatric or neurological illnesses. In addition, one must emphasise the general decreased ability of this population to care for themselves, especially under adverse environmental conditions. There are significant socioeconomic disadvantages associated with neuropsychiatric illnesses. It is difficult for these patients to discern and compensate for temperature changes. These factors, in addition to the impact of the anticholinergic agents typically used in management of psychiatric disorders, make the heatstroke season a very dangerous time of year for these patients. When exceedingly hot weather is predicted, the patient and involved family members need to be informed of what precautions to take and told to seek immediate medical care if signs or symptoms develop. Consideration should also be given to discontinuing or reducing medication.

LEWIS GOLDFRANK

Department of Medicine,

Albert Einstein College of Medicine

ROBERT DAVIS

Department of Psychiatry,

Albert Einstein College of Medicine

Michael DUNFord

Montefiore Hospital and Medical Center,

New York 10467, USA

\section{Prevalence of acne}

SIR,--Various factors, including the contraceptive pill, may influence the prevalence of acne in women, as Drs W J Cunliffe and D J Gould point out (28 April, p 1109). We examined 108 healthy women on the contraceptive pill and compared the severity of acne with that in healthy age-matched controls not receiving the pill. The significance of the results was determined by the $\chi^{2}$ test. No statistical difference in severity of acne was found between the two groups. The number of patients was not large enough to analyse a breakdown of different pills.

If the contraceptive pill does influence acne, this can be established only by examining a larger group of women and correlating the severity of their acne with pills of different oestrogenic and progestogenic activity.

\section{P V HARRISON}

B DODMAN

Department of Dermatology,

W J CUNLIFFE

\section{General Infirmary,
Leeds LS1 3EX}

\section{AID for lesbians}

SIR,-I was utterly dismayed to hear that the chairman of the BMA's Ethical Committee considers that the use of artificial insemination by donor for a lesbian requesting it does not so much pose an ethical dilemma, but that the important issue is that the doctor should have the "right" to decide, in any particular case, whether or not AID would be appropriate for his patient.

Even if one were to ignore the ethical aspect (heaven forbid), what "right" have any of us to assume that we can ever possess such foresight and perception to back a decision that it would not be unreasonable to accede to the woman's request and arrange AID for her? How can we ever predict the psychological trauma that might afflict a child conceived in this way?

To have collaborated at all in such an event would carry with it an implicit belief, on the part of the doctor, that untold psychological harm will not, in all probability, result. Don't let any of us imagine for a moment that we know all the answers. And as we do not and cannot, let the possible and indeed probable implications for the child be paramount.

In any case, the ethical aspect remains. May we hear from the chairman what he considers the ethical aspects are in this issue, if any?

Bakewell, Derbyshire

I M Cosgrove

***We sent a copy of this letter to the chairman of the Ethical Committee, whose reply is

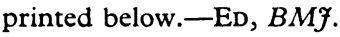

SIR,-I am worried in case Dr Cosgrove has misinterpreted the report from the ARM on AID for lesbians. My advice to the Representative Body at the end of a long debate was that the wording of the motion was asking the BMA to make a moral judgment on a form of treatment. AID is treatment and like other forms of treatment which involve questions of personal conscience its provision can lead doctors into an ethical dilemma. The Centrat Ethical Committee knows of no circumstances where the BMA has prescribed or denied any treatment on moral grounds. The committee always considered that in a personal medical service a doctor has a duty to treat each person on the basis of individual need.

A doctor, when providing AID, takes an active part in the conception of a child, and in these circumstances his primary responsibility is to that unborn child. It may be that after consideration every doctor might decide that he was unable to foresee the effects of his treatment and could not therefore co-operate in its provision. But that is his personal decision, which will probably reflect his own moral values.

Michael J G Thomas

London WC1H 9JP

Chairman,

\section{Abortion}

SIR,-May I be allowed to comment on one aspect of the Abortion (Amendment) Bill, as I find your leading article (28 July, p 230) somewhat confused? You appear to argue that, because the Abortion Act 1967 is not intended to affect the provisions of the Infant Life (Preservation) Act 1929, whereby it is an offence to destroy the life of a child capable of being born alive, there is no case for any amendment to either Act.

For more than a decade now it has been recognised that a small-perhaps very small but nevertheless significant-number of fetuses born before the 28 th week of pregnancy have survived and developed into healthy children. This number may well increase as the knowledge and techniques applied to neonatology advance. The advisory group (of which I was chairman) established by the DHSS some years ago to report on "the use of foetuses and fetal material for research" recognised this fact and, for reasons which I need not elaborate here, recommended that amending legislation should be introduced to the Infant Life (Preservation) Act to alter 28 weeks to 20 weeks as the date from which a fetus could be regarded as "capable of being born alive," and furthermore that this figure should be kept under constant review in the light of increased developments in neonatal care. There is room for discussion whether 20 weeks is the right date at this time, but there would seem to be little justification for maintaining 28 weeks as realistic.

What the Infant Life (Preservation) Act does not say is that a fetus born before the $28 \mathrm{th}$ week is necessarily incapable of being born alive, and it can be argued with ample justification that many of the very late abortions carried out under the 1967 Act are in fact contravening the spirit, if not the exact letter, of the law. It would be a pity if this opportunity were to be missed of amending both Acts in this particular respect and also the regulations dealing with the notification and registration of births. Obstetricians and paediatricians the world over have long accepted the view that 28 weeks is no longer a realistic assessment of so-called viability.

JoHN PeEL

West Tytherley, nr Salisbury, Wilts SP5 1LU

SIR,-Your leading article "No case for an abortion Bill" (28 July, p 230) implies that all the moral questions surrounding abortion have been satisfactorily resolved and that only practical and legal difficulties remain. It also attempts to dismiss the views of those conscientiously opposed to abortion by claiming that "incredulity will, surely, soon apply to attempts by the criminal law to control termination of pregnancy in its early weeks."

There are practical problems associated with late abortions, but these problems are small in comparison with the injustice of killing 